\title{
Ages of mantle metasomatism from U-Th-He systematics of diamond-forming $\mathrm{C}-\mathrm{O}-\mathrm{H}$ fluids
}

\author{
Yaakov Weiss, Cornelia Class, Steven L. Goldstein and Gisela Winckler \\ Lamont-Doherty Earth Observatory of Columbia University, New York, United States, yweiss@ldeo.columbia.edu
}

\section{Introduction}

Carbon and water-rich (C-O-H) mantle fluids play a major role in metasomatism of the deep sub-continental lithospheric mantle (SCLM). Yet the origin and composition of the fluids involved and, in particular, the timing of metasomatic fluid-rock interaction, is still poorly constrained. 'Fibrous' diamonds form over short time intervals during metasomatism by percolating $\mathrm{C}-\mathrm{O}-\mathrm{H}$ fluids in the SCLM. Fibrous diamonds commonly encapsulate C-O-H fluids as $\mu$ m-scale high-density fluid (HDF) inclusions, which can be directly sampled. Due to the physical strength and chemically inert nature of their diamond host, these HDF inclusions remain pristine for billions of years even when brought to Earth's surface. They thus offer a unique opportunity to investigate metasomatic events involving $\mathrm{C}-\mathrm{O}-\mathrm{H}$ mantle fluids and the SCLM through Earth's history. But until now no technique has been able to provide direct and reliable age constraints on HDFs.

Here we explore the radioactive U-Th-He system in HDF microinclusions-bearing fibrous diamonds as a tool for providing meaningful radiometric ages of C-O-H mantle fluids, and to constrain the timing of metasomatic events in the SCLM. The HDFs in 'fibrous' diamonds exhibit high helium concentrations up to $\sim 10^{-5} \mathrm{ccSTP} / \mathrm{g}$, and are enriched in incompatible elements (including $\mathrm{U}$ and Th). Nonetheless, only few such diamonds have been analyzed until now for their $\mathrm{He}$ contents and ${ }^{3} \mathrm{He} /{ }^{4} \mathrm{He}$ ratios, despite the great opportunities they provide for investigating deep mantle volatiles. We have developed an in-vacuum crushing technique for determining the $\mathrm{He}$ concentrations and ${ }^{3} \mathrm{He} /{ }^{4} \mathrm{He}$ ratios in the trapped HDFs. Combined with EPMA and LA-ICP-MS analyses of major and trace element abundances of HDFs in the same diamonds, we determine the amount of $\mathrm{U}$, Th and He in the fluids themselves, as opposed to their concentrations in the bulk diamonds. Below we present preliminary data and show that HDF type and ${ }^{3} \mathrm{He} /{ }^{4} \mathrm{He}$ ratios are related. In addition, diamonds from the Kimberley cluster and the Finsch mine, South Africa, reveal 3 metasomatic events in the southwestern Kaapvaal SCLM during the last $\sim 1$ Gyr, each by a different metasomatic agent. The youngest episode indicates direct relationships between metasomatism by highly saline fluids, fibrous diamond formation and late-Mesozoic kimberlite eruptions.

\section{Helium contents and ${ }^{3} \mathrm{He} /{ }^{4} \mathrm{He}$ ratios in different $\mathrm{C}-\mathrm{O}-\mathrm{H}$ mantle fluid-types}

HDFs in fibrous diamonds vary in major-element compositions between four major types: silicic, saline, and high-Mg and low-Mg carbonatitic. Moreover, they display two main trace-element patterns, one with high field strength element (HFSE) depletions and large ion lithophile element (LILE) enrichments, similar to calcalkaline magmas and continental rocks, the other with lower LILE abundances and 'smoother' overall trace-element patterns, similar to oceanic basalts. Thus, HDFs record a large range of compositions and sources for the metasomatic C-O-H mantle fluids. Recently, Weiss et al. (2015) reported the first conclusive trace-element and $\mathrm{Sr}$ isotope evidence for seawater-altered subducting slabs as the source of deep $\mathrm{C}-\mathrm{O}-\mathrm{H}$-bearing mantle fluids having saline compositions, and that these fluids are parental to carbonatitic and silicic melts formed in-situ within the lithosphere.

We report $\mathrm{He}$ contents and ${ }^{3} \mathrm{He} /{ }^{4} \mathrm{He}$ ratios of $\mathrm{HDFs}$ in 15 fibrous diamonds, previously analyzed for their major-element compositions. Excluding three diamonds having non-saline $\mathrm{HDFs}$ with radiogenic ${ }^{3} \mathrm{He} /{ }^{4} \mathrm{He}$ signatures (see discussion below), the saline HDFs have the lowest ${ }^{3} \mathrm{He} /{ }^{4} \mathrm{He}$ ratios (Fig. 1a). Our preliminary 
He analyses on 6 diamonds carrying saline HDFs strengthen the connection between saline-type deep C$\mathrm{O}-\mathrm{H}$ fluids and recycled subducted surface material, based on their low ${ }^{3} \mathrm{He} /{ }^{4} \mathrm{He} \approx 3.5 \mathrm{R}_{\mathrm{A}}$ (where $\mathrm{R}_{\mathrm{A}}$ is the atmospheric ratio of $\left.1.39 \times 10^{-6}\right)$. Also, ${ }^{3} \mathrm{He} /{ }^{4} \mathrm{He}$ ratios of $\mathrm{HDFs}$ and the amount of $\mathrm{K}_{2} \mathrm{O}$ (in wt.\%) and carbonate component (expressed as $(\mathrm{MgO}+\mathrm{FeO}+\mathrm{CaO}) / \mathrm{SiO}_{2} / \mathrm{Cl}$; Fig. 1b) correlate. This may reflect the involvement of subduction-related saline fluids in the formation of silicic and carbonatitic HDFs within the lithosphere, as concluded by Weiss et al. (2015). The South African silicic and carbonatitic diamonds have more radiogenic ${ }^{3} \mathrm{He} /{ }^{4} \mathrm{He}$ ratios compared to saline diamonds from the same kimberlite pipes, and much lower ${ }^{3} \mathrm{He} /{ }^{4} \mathrm{He}$ compared to silicic and carbonatitic diamonds from Botswana and Guinea (Fig. 1). This could suggest a complex evolution of diamond source fluids. Alternatively, the varying ${ }^{3} \mathrm{He} /{ }^{4} \mathrm{He}$ signatures of different $\mathrm{C}-\mathrm{O}-\mathrm{H}$ fluid compositions could represent different metasomatic events at different times over the history of local continental mantle.
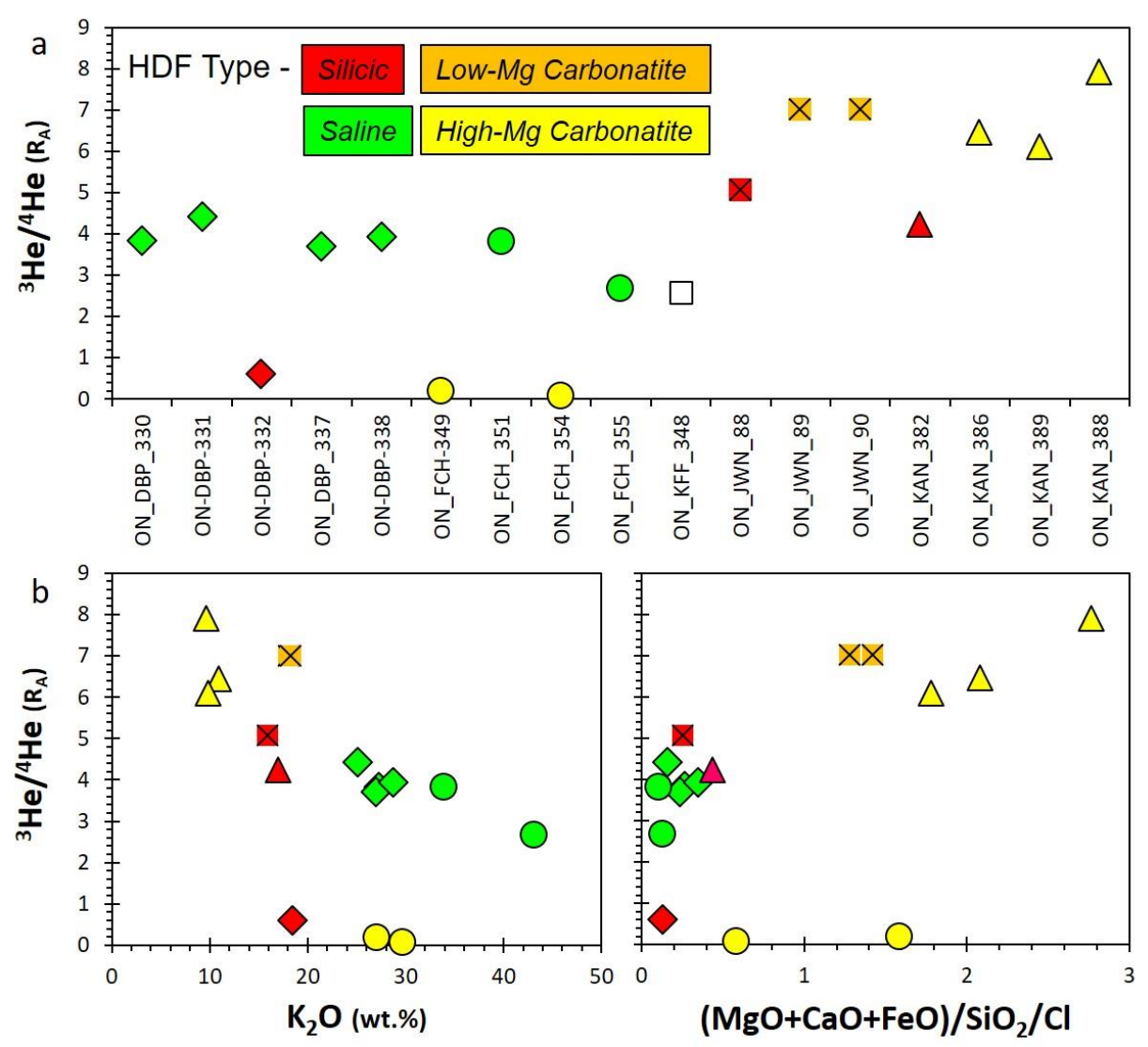

Figure 1: ${ }^{3} \mathrm{He} /{ }^{4} \mathrm{He}$ ratio (in $\mathrm{R}_{\mathrm{A}}$ ) of different $\mathrm{HDF}$ compositionsl types. (a) ${ }^{3} \mathrm{He} /{ }^{4} \mathrm{He}\left(\mathrm{R}_{\mathrm{A}}\right)$ of 17 diamonds from DeBeersPool (DBP), Finsch (FCH) and Koffiefontein (KFF; HDF type not yet determined), South Africa; Jwaneng (JWN), Botswana; Kanakan (KAN), Guinea. Data for the 2 low-Mg carbonatitic diamonds from Jwaneng are from Schrauser and Navon (1994) and Burgess et al. (1998). (b) ${ }^{3} \mathrm{He} /{ }^{4} \mathrm{He}\left(\mathrm{R}_{\mathrm{A}}\right)$ against $\mathrm{K}_{2} \mathrm{O}$ (in wt.\%) and against $(\mathrm{MgO}+\mathrm{FeO}+$ $\mathrm{CaO}) / \mathrm{SiO}_{2} / \mathrm{Cl}$, expressing the amount of carbonate in the $\mathrm{HDF}$.

\section{A billion years of metasomatic alteration of the Kaapvaal SCLM encapsulated in fibrous diamonds}

The different kimberlites in the DeBeers-Pool cluster and the Finsch kimberlite are close in space and age and sample the southwestern part of the Kaapvaal SCLM. One Finsch and four DeBeers-Pool diamonds have high and uniform microinclusion densities, and an inner fragment of each diamond could be separated and analyzed for He. This prevents possible effects of implantation of ${ }^{4} \mathrm{He}$ from the surrounding host rock, or the loss of ${ }^{4} \mathrm{He}$ due to $\alpha$-recoil from the outer $<20 \mu \mathrm{m}$ of the diamond. U-Th-He ages were calculated for 
these diamonds. The saline HDFs in 3 of the DeBeers-Pool diamonds have very similar major and trace element compositions and low-aggregated states of nitrogen (IaA-type IR spectrum), suggesting their formation during a single metasomatic event by $\mathrm{C}-\mathrm{O}-\mathrm{H}$ fluids close in time to kimberlite eruption (Extended Abstract No. 11IKC-004461). Plotting these diamonds on a ${ }^{4} \mathrm{He} /{ }^{3} \mathrm{He} v s .{ }^{238} \mathrm{U} /{ }^{3} \mathrm{He}$ defines an isochron with an age of $96 \pm 45 \mathrm{Myr}$ (Fig. 2a). This result represents the first radiometric age reported for fibrous diamonds and the $\mathrm{C}-\mathrm{O}-\mathrm{H}$ mantle fluids they carry. In addition, 1 diamond from the DeBeers-Pool has silicic microinclusion compositions while 2 from Finsch carry carbonatitic HDFs. These diamonds display more radiogenic ${ }^{3} \mathrm{He} /{ }^{4} \mathrm{He}$ ratios of 0.59 and $0.17 \mathrm{R}_{\mathrm{A}}$ (Figure 1a), and associated aggregated nitrogen IaAB-type IR spectra with $25 \%$ and $32 \%$ B-centers, respectivaly, suggesting their formation during earlier and different metasomatic events.

Using the $\mathrm{U}$, Th, ${ }^{4} \mathrm{He}$ and ${ }^{3} \mathrm{He}$ contents of these diamonds, and the equation for ${ }^{4} \mathrm{He}$ production by $\mathrm{U}$ and $\mathrm{Th}$ decay, we calculate ${ }^{3} \mathrm{He} /{ }^{4} \mathrm{He}$ ratios as a function of time. Assuming that the $H D F$ initial $R / R_{A}$ values varied between 3-11, representing common values for MORB, the SCLM and subducted components, the silicic and carbonatitic HDFs represent two older metasomatic events that took place in the Kaapvaal SCLM at $\sim 350$ and $\sim 850$ Myr (Figure 2b). Thus, our new data reveal 3 episodes of chemical changes in the Kaapvaal SCLM during the last $\sim 1 \mathrm{Gyr}$, each by a different metasomatic agent. The youngest episode indicates direct relationships between highly-saline fluid metasomatism, fibrous diamond formation and lateMesozoic kimberlite eruptions, while the older silicic and carbonatitic metasomatic events may be related to the regional Namaqua-Natal Orogeny ( 1 Gyr), Damara Orogeny ( $500 \mathrm{Myr})$ or the Karoo magmatism ( 200 Myr).

Figure 2: (a) A ${ }^{4} \mathrm{He} /{ }^{3} \mathrm{He}$ vs. ${ }^{238} \mathrm{U} /{ }^{3} \mathrm{He}$ isochron diagram for 3 saline HDF-bearing diamonds from the DeBeers-Pool giving a diamond formation and metasomatism age of $96 \pm 45 \mathrm{Myr}$ (calculated based on the least squares fitting of a straight line with correlated errors). Error bars account for a possible $\pm 15 \%$ on the U concentrations, $\pm 2 \%$ on the ${ }^{4} \mathrm{He}$ and $\pm 5 \%$ on the ${ }^{3} \mathrm{He}$ content. (b) ${ }^{3} \mathrm{He} /{ }^{4} \mathrm{He}$ model ages for DeBeers-Pool and Finsch fibrous
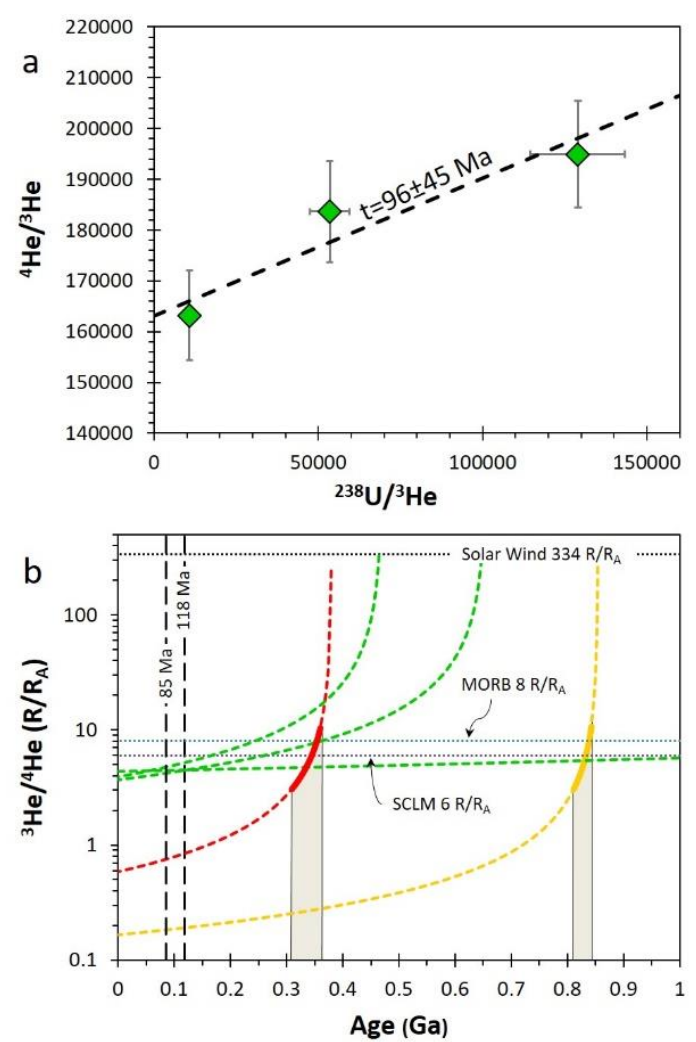
diamonds. The diagram illustrates ${ }^{3} \mathrm{He} /{ }^{4} \mathrm{He}$ ratios as a function of age for the different diamonds (dotted lines), calculated based on the measured ${ }^{3} \mathrm{He} /{ }^{4} \mathrm{He}$ and the ${ }^{4} \mathrm{He},{ }^{3} \mathrm{He}, \mathrm{U}$, and Th concentrations in these diamonds. Importantly, saline fluids (green - same diamonds as in 2a) controlled the metasomatism in the Kaapvaal craton before lateMesozoic kimberlite eruption (at $85 \mathrm{Myr}$ ), and that at least two additional metasomatic events by silicic (red - DeBeersPool) and carbonatitic (yellow - Finsch) $\mathrm{C}-\mathrm{O}-\mathrm{H}$ fluids took place in the Kaapvaal SCLM during the last $1 \mathrm{Gyr}$. If we assume an initial ${ }^{3} \mathrm{He} /{ }^{4} \mathrm{He}$ in the range of 3-11 $\mathrm{R}_{\mathrm{A}}$ (thick red and yellow lines), then these metasomatic events occurred at $\sim 350$ and $\sim 850 \mathrm{Myr}$.

\section{References}

Weiss Y, McNeill J, Pearson DG, Nowell GM, Ottley CJ (2015) Highly saline fluids from a subducting slab as the source for fluid-rich diamonds. Nature 524:339-342.

Burgess, R., Johnson, L.H., Mattey, D.P., Harris, J.W., Turner, G., 1998. He, Ar and C isotopes in coated and polycrystalline diamond. Chemical Geology 146, 205-217.

Schrauder, M., Navon, O., 1994. Hydrous and carbonatitic mantle fluids in fibrous diamonds from Jwaneng, Botswana. Geochimica et Cosmochimica Acta 58, 761-771. 